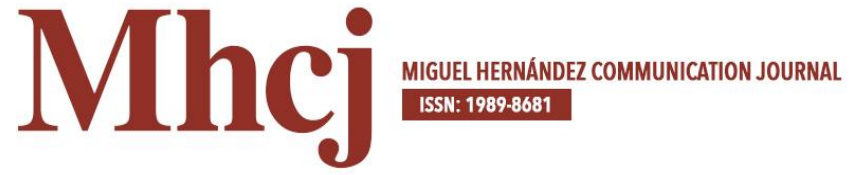

\title{
Reputação corporativa na Web: reflexões acerca da formação em Comunicação e da articulação de redes sociais no Brasil
}

\author{
Dra. Fabiana Grieco Cabral de Mello Vetritti| fabianagrieco@usp.br \\ Universidade de São Paulo \\ Dr. Rafael Vergili | rvergili@gmail.com \\ Universidade de São Paulo
}

\begin{abstract}
Palavras-chave
Reputação corporativa; Articulação das redes sociais;

Web; MIL - Literacias de Mídia e Informação;

Prosumer.

Sumário

1. Introdução 2. Metodologia 3. MIL 4. Características do mercado brasileiro de articulação de redes sociais

5. Defasagem na formação dos profissionais de Comunicação que articulam redes sociais de grandes empresas 6. Análise de Instituições de Ensino Superior que oferecem o curso de Graduação em Comunicação (Relações Públicas): pesquisa qualitativa e pesquisa documental 7. Identidade, imagem e reputação: relacionamento entre empresas e stakeholders com o intuito de fortalecimento da reputação corporativa na rede 8. Considerações Finais 9. Referências 10. Notas
\end{abstract}

\section{Resumo}

Fenômenos como a disseminação dos dispositivos móveis, o aumento dos níveis de acesso à Internet, a participação da população conectada no consumo e na produção de conteúdo têm sido observados no Brasil nas últimas décadas. Os avanços da cibercultura na sociedade contemporânea brasileira delineiam um cenário marcado pela liquidez dos padrões e pela emergência de novas formas de configuração entre indivíduos e organizações. Diante disso, este texto trata do mercado brasileiro de articulação de redes sociais e seus profissionais, contemplando a formação nas Instituições de Ensino Superior e as

habilidades e competências no uso da mídia e informação, definidas pela Unesco como MIL. Para tanto, foram realizadas pesquisa quantitativa e qualitativa, conforme os procedimentos adotados no livro "Relações Públicas, Mercado e Redes Sociais", de "Autor deste artigo" (2014), e da Tese de Doutorado, publicada pelo mesmo autor (2017). As pesquisas buscaram driblar os desafios de penetrar no universo das organizações brasileiras e dialogar com os profissionais do mercado e das instituições de ensino que lecionam Relações Públicas. Acredita-se que o presente texto sinalize a necessidade de estratégias de longo prazo para o fortalecimento da reputação corporativa na Web.

\section{Cómo citar este texto:}

Fabiana Grieco Cabral de Mello Vetritti y Rafael Vergili (2017): "Reputação corporativa na Web: reflexões acerca da formação em Comunicação e da articulação de redes sociais no Brasil”, en Miguel Hernández Communication Journal, nº 8 , pp. 435 a 464 . Universidad Miguel Hernández, UMH (Elche-Alicante). Recuperado el _ de de 20 de: @ink del artículo en mhjournal.org] 


\title{
Corporate Reputation on the Web: reflections about Communication learning programs and social media management in Brazil
}

\author{
Dra. Fabiana Grieco Cabral de Mello Vetritti| fabianagrieco@usp.br \\ Universidade de São Paulo \\ Dr. Rafael Vergili | rvergili@gmail.com \\ Universidade de São Paulo
}

\begin{abstract}
Keywords
Corporate Reputation; Social media

management; Public Relations professional;

Web; MIL - Media and Information Literacy;

Prosumer.

Summary

1. Introduction 2. Methodology 3. MIL - Media and Information Literacy 4. Characteristics of the Brazilian social networking market 5. Gap in Communication learning programs devoted to professionals that manage social media for large companies 6. Analysis of Higher Education Institutions that offer Bachelor of

Communication (Public Relations): qualitative research and documentary research 7. Identity, image and reputation: relationship between companies and stakeholders with the purpose of strengthening the corporate reputation in social networks 8. Final Considerations 9. References 10. Notes
\end{abstract} the book "Relações Públicas, Mercado e Redes Sociais", authored by "Author of this article" (2014), and the Doctoral Thesis, published by the same author (2017). The research aimed to overcome the challenges faced to penetrate the universe of Brazilian organizations and to dialogue with market professionals and from educational institutions that teach Public Relations. It is believed that the present text highlight the need for long-term strategies to strengthen corporate reputation on the Web.

\section{How to cite this text:}

Fabiana Grieco Cabral de Mello Vetritti y Rafael Vergili (2017): “Corporate Reputation on the Web: reflections about Communication learning programs and social media management in Brazil", en Miguel Hernández Communication Journal, nº8, pp. 435 to 464. Universidad Miguel Hernández, UMH (Elche-Alicante). Accessed link in mhjournal.org] 


\section{Introdução}

Os avanços tecnológicos, especialmente nos últimos anos, contribuíram para reconfigurar os modelos de negócio consolidados há décadas. O aumento considerável de acessos à Internet, sobretudo decorrente da ampla oferta de dispositivos móveis, como telefones inteligentes (smartphones), ultrabooks, tablets, e-readers, apresenta diversos desafios e oportunidades para o relacionamento entre empresas e públicos de interesse.

No Brasil, é cada vez mais notória a presença da população na Web e a participação dos usuários nas redes sociais. Segundo a pesquisa TIC Domicílios 2015, ${ }^{11}$ do Comitê Gestor da Internet no Brasil (Cgi.br), realizada anualmente pelo Centro Regional de Estudos para o Desenvolvimento da Sociedade da Informação (Cetic.br), do Núcleo de Informação e Coordenação do Ponto BR (Nic.br), em 2015, 50\% dos domicílios possuem acesso ao computador e 51\% acesso à Internet, índices estáveis em relação aos de 2014.

A pesquisa TIC Domicílios 2015 também revela que os usuários da rede correspondem a 58\% da população com 10 anos ou mais. Desse montante, $89 \%$ acessam a Internet pelo telefone celular, e $65 \%$ por meio de um computador de mesa, portátil ou tablet. Embora mais da metade da população tenha acesso à Internet, nota-se a desigualdade socioeconômica com apenas $16 \%$ dos domicílios da classe D e E conectados à Internet. Em termos regionais, o acesso ocorre em 56\% dos domicílios de áreas urbanas e apenas em $22 \%$ na área rural.

Considerando o contexto de ampliação do acesso à Internet, ainda que em meio a um cenário caracterizado pela desigualdade socioeconômica e regional, é fundamental reconhecer a disseminação do uso das redes sociais pela população conectada. A pesquisa Digital Future Focus Brazil 2015, divulgada pela consultoria comScore (Otoni, 2015), revela que os brasileiros são líderes no tempo gasto nas redes sociais. Isso representa 650 horas nas redes sociais por mês, 290 horas a mais do que navegando em portais de notícias.

A identificação de que o brasileiro é um dos principais usuários de redes sociais do mundo suscita um debate acerca não apenas focado no usuário, mas nos profissionais de articulação das redes sociais. A quantidade de horas dispendida, bem como o engajamento dos usuários, instiga as organizações a atuarem de modo estratégico nas redes. Com foco na produção de informação e nas organizações desse segmento, Beth Saad (2012, p. 62) pontua a 
fragilidade do domínio do processo produtivo com a interferência ativa do usuário, destacando que:

“[...] o negócio da informação digital provoca mudanças significativas no fluxo de geração de mensagens com a inserção do conceito de agregação - atividade de formatação da informação conforme as características do meio e do seu público-alvo. Também emerge com destaque o papel do usuário, ou seja, o conhecido leitor agora equipado com seu arsenal particular de informática e telecomunicações que tem o poder - a ele conferido pela própria tecnologia - de selecionar os conteúdos, as informações, os serviços, as notícias que lhe interessam."

Em consonância com a afirmativa de Saad sobre as empresas informativas, Margarida Kunsch indica que as organizações, independentemente do segmento, necessitam de uma filosofia além do marketing para enfrentar os desafios do contemporâneo, valendo-se "de serviços integrados nessa área, pautando-se por políticas que privilegiem o estabelecimento de canais efetivos de diálogos com os segmentos a elas vinculados e, principalmente, a abertura das fontes e a transparência de suas ações" (2007, p. 42). Nesse contexto, Kunsch salienta a figura do relações públicas.

Partindo da premissa da criação de canais de diálogos e da oferta da comunicação integrada, composta por comunicação mercadológica, institucional e interna/administrativa (Kunsch, 2003), o RP é um dos profissionais cuja importância destaca-se em meio aos demais colaboradores atuantes no âmbito da comunicação organizacional. Sob essa perspectiva, o exercício do relações-públicas também contempla a atuação na interface digital e relacionamento com a população conectada, através da articulação das redes sociais.

Entre outros aspectos, o aumento de conexões de Internet, a facilitação do acesso à rede por meio de dispositivos móveis e a dedicação de horas dos usuários brasileiros trazem consigo uma demanda de comunicação estratégica digital por parte das organizações e de profissionais de relações públicas habilitados ao exercício do diálogo por meio das redes sociais. 
Diante disso, este artigo tem o objetivo de analisar o mercado brasileiro de articulação de redes sociais e seus profissionais de Comunicação, contemplando a formação nas Instituições de Ensino Superior (IES) e as MIL inseridas no processo de aprendizagem, tendo como pano de fundo a noção de reputação corporativa na Web.

Acredita-se que os dados aqui apresentados possam contribuir com a noção de reputação na Web, a partir da compreensão do cenário das organizações brasileiras e das IES que promovem a formação dos profissionais de Comunicação que atuam com comunicação digital e redes sociais. Além disso, ilumina os contornos sobre o uso da mídia e informação e sua apropriação sob a ótica das MIL - Literacias de Mídia e Informação, estabelecido pela Organização das Nações Unidas para a Educação, a Ciência e a Cultura (Unesco).

\section{Metodologia}

Diversos procedimentos metodológicos foram adotados para contemplar o objetivo do trabalho, exposto anteriormente, na "Introdução". Os mais utilizados: revisão de literatura, pesquisa quantitativa, pesquisa qualitativa e pesquisa documental.

O artigo, de certo modo, apresenta um estudo iniciado em 2012, de "Autor deste artigo" (2014), publicado como livro em 2014. A continuação da pesquisa deu origem a uma Tese, publicada em 2017 pelo mesmo autor. A junção dos resultados obtidos nas Teses de "Autora deste artigo" (2017) e "Autor deste artigo" (2017), ambas tendo como fio condutor a tecnologia e as MIL - Literacias de Mídia e Informação, habilidades e competências para lidar com plataformas digitais, conduzem o leitor ao longo do presente artigo.

Diante disso, o item "MIL - Literacias de Mídia e Informação" aborda o contexto da modernidade fluida, do ambiente digital, da emergência das MIL, um conjunto de habilidades e competências referentes ao uso da mídia e informação preconizado pela Unesco, e dos "prosumers", usuários que além de consumirem, também produzem conteúdo por meio da Web. Obras de Zygmunt Bauman (2001, 2013) Alvin Toffler (1980), Bruno Latour (2012), “Autora deste artigo" (2017), Manuel Castells (2003) e Pierre Lévy (1999) são usadas como base para a reflexão sobre o tópico.

Posteriormente, no item "Características do mercado brasileiro de articulação de redes sociais" apresentam-se os principais resultados de uma pesquisa 
quantitativa, desenvolvida por "Autor deste artigo" (2014), que além das informações apresentadas neste artigo, na obra original "Relações públicas, mercado e redes sociais", detalha os procedimentos metodológicos adotados e retrata o perfil completo de profissionais de articulação de redes sociais.

De modo sucinto, o universo da pesquisa foi composto por uma série de etapas metodológicas, descritas em mais detalhes na obra original supracitada, mas que partiu do ranking "Melhores \& Maiores" divulgado anualmente pela revista Exame (2013). Depois de visitar o website oficial de cada uma das mil empresas listadas no ranking, identificou-se que 252 das maiores empresas do Brasil divulgam contas oficiais em redes sociais (Twitter, Facebook e/ou Fllickr), o que representa $25,2 \%$ do total analisado.

A partir daí, entre 04 e 15 de novembro de 2013, foi enviado um questionário estrutura on-line, com questões, por tweet (mensagem aberta do Twitter) para todas as 252 empresas. Foram obtidas 128 respostas (50,8\%), utilizando-se o método de coleta de dados via autopreenchimento.

Após tabulação dos dados, treze aspectos importantes sobre o mercado de articulação de redes sociais puderam ser destacados, como o perfil pessoal e profissional dos envolvidos com as ações corporativas na Web, o departamento responsável pelas atividades na rede, entre outras características. Os percentuais relativos a cada variável mencionada podem ser observados em detalhes na obra original de "Autor deste artigo" (2014). Neste trabalho, especificamente, destacam-se: o principal objetivo de atuação das empresas no ambiente digital; o percentual de serviços prestados internamente ou de modo terceirizado; e a área responsável pela articulação de redes sociais.

No item "Defasagem na formação dos profissionais de Comunicação que articulam redes sociais de grandes empresas", percebendo-se que as primeiras colocadas no ranking "Melhores e Maiores" - utilizado na pesquisa quantitativa previamente apresentada - possuíam serviços prestados de forma terceirizada, decidiu-se apresentar seis entrevistas em profundidade realizadas com representantes de grandes Agências de Comunicação brasileiras ${ }^{22}$, que faziam a articulação de redes sociais para algumas das maiores empresas brasileiras, baseando-se, em especial, no Anuário Brasileiro da Comunicação Corporativa (2012).

É nesse contexto que no item "Análise de Instituições de Ensino Superior que oferecem o curso de Graduação em Comunicação (Relações Públicas): pesquisa qualitativa e pesquisa documental", apresentam-se alguns dos resultados obtidos na Tese de Doutorado de "Autor deste artigo" (2017), 
intitulada "Literacias digitais nos cursos de Graduação em Relações Públicas: disciplinas de tecnologia nas matrizes curriculares de universidades brasileiras”, em que foram realizadas duas pesquisas, sendo uma qualitativa e uma documental, com o objetivo de avaliar se as universidades brasileiras aumentaram a carga horário e o número de disciplinas de tecnologia em suas matrizes curriculares.

Para realizar a pesquisa qualitativa, previamente foram mapeados todos os cursos de Graduação em Relações Públicas oferecidos no Brasil. Para isso, diversos procedimentos foram adotados, desde a coleta dados, passando pela confirmação de informações compiladas e a definição de um universo, até a seleção das universidades que teriam seus representantes entrevistados.

Adotou-se, em primeiro lugar, o portal oficial do MEC como ponto de partida para a elaboração da lista de cursos de Graduação em Relações Públicas oferecidos no país. Nesse sentido, explorou-se a base de dados e-MEC ${ }^{33}$, que tem relação direta com as IES brasileiras.

Escolheu-se, em um primeiro momento, a guia "Consulta Avançada", que possibilita a procura específica por curso. Neste caso, selecionou-se a opção por "Curso de Graduação", realizando-se o preenchimento do campo com o termo "Relações Públicas", sem definir nenhum Estado específico para a consulta, o que possibilitou uma visão do panorama nacional.

Dessa consulta, a própria base de dados gerou uma lista com 111 Instituições de Ensino Superior que oferecem o curso de Graduação em Relações Públicas, entre "em atividade", "em extinção" e "extintos". A partir daí, clicou-se no nome de cada uma das 111 IES listadas, o que gerou uma ficha individual com dados referentes ao número de registro do curso, "modalidade" (presencial ou EaD), "grau" (Bacharelado, por exemplo), "curso" (Relações Públicas), "Estado", "munícipio", além de notas referentes ao "ENADE" (Exame Nacional de Desempenho de Estudantes), "CPC" (Conceito Preliminar de Curso) e "CC" (Conceito de Curso).

Posteriormente, escolheu-se a guia "Consulta Interativa", que apresenta um mapa com todos os Estados do Brasil. Clicou-se em cada Estado do mapa. Em seguida, selecionou-se o curso (no caso, Relações Públicas) e o município para análise de IES listadas. Os principais dados coletados foram: endereço, telefone, website oficial e e-mail da IES; Organização Acadêmica (Faculdade, Centro Universitário ou Universidade); Categoria Administrativa (Pública Estadual, Pública Federal, Privada com fins lucrativos ou Privada sem fins lucrativos, por exemplo); além de notas referentes ao "CI" (Conceito 
Institucional), "IGC" (Índice Geral de Cursos) e "IGC Contínuo" (Índice Geral de Cursos Contínuo).

Todos os dados supracitados foram reunidos entre os dias 17 e 22 de maio de 2016, formando uma lista de 111 cursos de Relações Públicas. Nos dias subsequentes, entre 23 e 27 de maio de 2016, buscou-se confirmação telefônica para avaliar quais cursos de Relações Públicas ainda estariam em atividades em 2016 e abririam novas turmas em 2017. Depois das ligações, constatou-se que 56 cursos de Graduação em RP estão em plena atividade no Brasil.

A partir desse cenário, analisou-se que dos 56 cursos, 40 estão disponíveis em IES privadas (71,4\%), 15 em universidades públicas (26,8\%) e 1 em uma categoria "Especial" (1,8\%).

Com relação à Organização Administrativa do âmbito geral, que abrange os 56 cursos oferecidos, percebe-se maior concentração em "Universidades", com 34 cursos oferecidos (60,7\%). Faculdades, com 15 cursos (26,8\%), e Centros Universitários, com 7 cursos de RP (12,5\%), aparecem na sequência.

No que tange às regiões brasileiras, nota-se que a maioria das IES estão situadas no Sudeste do Brasil, com 32 cursos (57,1\% do total). Em seguida, aparecem: Sul, com 14 cursos (25,0\%); Nordeste, com 7 (12,5\%); CentroOeste, com 2 (3,6\%); e Norte, com 1 curso (1,8\%).

Para selecionar os 10 cursos de Graduação em Relações Públicas que seriam entrevistados e teriam suas matrizes curriculares analisadas, tentou-se seguir uma proporção mínima a respeito das regiões brasileiras, da Categoria Administrativa, da Organização Acadêmica, e dos conceitos de IGC ${ }^{44}$ e IGC Contínuo ${ }^{55}$. Portanto, a seleção baseou-se somente em critérios técnicos, sem considerar quais seriam os cursos mais conhecidos (top of mind) do Brasil, por exemplo.

Ao final de todo o processo, as 10 universidades selecionadas foram: Universidade Federal de Minas Gerais (UFMG); Universidade Estadual Paulista "Júlio de Mesquita Filho" (Unesp); Universidade Católica de Santos (Unisantos); Pontifícia Universidade Católica de Minas Gerais (PUC Minas); Universidade Anhembi Morumbi (UAM); Universidade de São Paulo (USP), Universidade Federal do Rio Grande do Sul (UFRGS); Universidade do Vale do Rio dos Sinos (Unisinos); Pontifícia Universidade Católica do Rio Grande do Sul (PUCRS); e Universidade Salvador (Unifacs). 
$\mathrm{Na}$ pesquisa qualitativa, as 10 entrevistas em profundidade, com representantes de universidades, foram realizadas entre os dias 23 de agosto e 21 de setembro de 2016, com auxílio de um roteiro semiestruturado de entrevistas. Com cerca de dez horas e meia de gravações, transcritas e apresentadas integralmente em 155 páginas da Tese de "Autor deste artigo" (2017), seguiu-se a divisão por "categorias temáticas".

A obra "Análise de Conteúdo", de Bardin (2016), foi a principal referência utilizada no presente artigo para a análise e interpretação dos dados coletados nas entrevistas, utilizando-se diversas técnicas, de forma conjunta, para agrupar elementos que tivessem afinidade, permitindo uma avaliação mais organizado, coesa e planejada.

Os depoimentos e resultados mais significativos que foram alcançados por meio da pesquisa qualitativa podem ser observados no decorrer do artigo. E é diante dessas declarações que confirmou-se o nome das disciplinas de tecnologia nas 10 matrizes curriculares de 2013 e de 2016, permitindo, posteriormente, uma análise do aumento na carga horária relativa a essa temática no período mencionado. Ou seja, basicamente uma pesquisa documental, que, de acordo com Antônio Joaquim Severino (2016, p. 131), refere-se a uma investigação sobre documentos que ainda não tiveram tratamento analítico. No caso, as matrizes curriculares.

Os principais resultados obtidos, tanto por meio da pesquisa qualitativa, como por meio da pesquisa documental, podem ser observados no item "Análise de Instituições de Ensino Superior que oferecem o curso de Graduação em Comunicação (Relações Públicas): pesquisa qualitativa e pesquisa documental".

Por fim, o item "Identidade, imagem e reputação: relacionamento entre empresas e stakeholders ${ }^{66}$ com o intuito de fortalecimento da reputação corporativa na rede", tendo como referência Paul Argenti (2006), Fábio França (2010) e Paul Capriotti (2005), inicialmente trata das diferenças conceituais entre identidade, imagem e reputação.

Também se destaca, com auxílio de obras de Jim Macnamara (2010), Luiz Alberto de Farias (2009) e Margarida Maria Krohling Kunsch (2003), a importância da manutenção de diálogo constante entre empresas e públicos de interesse, objetivando-se a reconstrução, a manutenção e/ou o fortalecimento da reputação corporativa por meio da Web. Conclui-se o item com as alterações provocadas no gerenciamento e mensuração dessa reputação, especialmente em decorrência das inovações tecnológicas, com auxílio de 
textos de Elisabeth Barbieri Lerner (2006), Jakob Nielsen (1999) e Luiz Carlos Assis Iasbeck (2007).

\section{MIL - Literacias de Mídia e Informação}

O sociólogo polonês Zygmunt Bauman revelou inúmeras transformações que compõem o que chamou de "modernidade líquida", marcada pelos fenômenos efêmeros e transitórios. Segundo Bauman (2001), o convívio humano e as condições sociais, por exemplo, são aspectos que sofreram mudanças profundas.

O poder pode se mover com a velocidade do sinal eletrônico - e assim o tempo requerido para o movimento de seus ingredientes essenciais se reduziu a instantaneidade. Em termos práticos, o poder se tornou verdadeiramente extraterritorial, não mais limitado, nem mesmo desacelerado, pela resistência do espaço (o advento do telefone celular serve bem como 'golpe de misericórdia' simbólico na dependência em relação ao espaço: o próprio acesso a um ponto telefônico não é mais necessário para que uma ordem seja dada e cumprida. Não importa mais onde está quem dá a ordem - a diferença entre 'próximo' e 'distante', ou entre o espaço selvagem e o civilizado e ordenado, está a ponto de desaparecer).

Nesse sentido, os avanços da Internet e dos dispositivos digitais figuram entre as transformações que impactam diversas esferas da sociedade contemporânea. No final da década de 1990, Pierre Lévy (1999, p. 17) tratou de abarcar parte desses fenômenos ao definir ciberespaço e cibercultura da seguinte maneira:

O ciberespaço (que também chamarei de 'rede') é o novo meio de comunicação que surge da interconexão mundial dos computadores. O termo especifica não apenas a infraestrutura material da comunicação digital, mas também o universo oceânico de informações que ela abriga, assim como os seres humanos que navegam e alimentam esse universo. Quanto ao neologismo 'cibercultura', especifica aqui o conjunto de técnicas (materiais e intelectuais), de práticas, de atitudes, de modos de pensamento e de valores que se desenvolvem juntamente com o crescimento do ciberespaço.

A interpretação do ciberespaço como "espaço de comunicação aberto pela interconexão mundial dos computadores e das memórias dos computadores" (Lévy, 1999, p. 92) e da composição do programa da cibercultura com três princípios: interconexão, criação de comunidades virtuais e inteligência 
coletiva, dialogam com os achados de Manuel Castells naquele período, sobretudo no que se refere à noção de comunidades virtuais e sociedade em rede. Como sugere Castells (2003, p. 107), "a grande transformação da sociabilidade em sociedades complexas ocorreu com a substituição de comunidades espaciais por redes como formas fundamentais de sociabilidade".

A apropriação da Internet pela prática social corresponde, entre outras coisas, à conexão de pessoas e máquinas, ocorrência mais recentemente observada por Bruno Latour em sua teoria do Ator-Rede. Sob o acrônimo ANT (ActorNetwork Theory), Latour (2012) retoma o significado original da palavra social para apontar uma sociologia das associações. Assim, estabelece conexões entre aquilo que comumente recebe o rótulo de "social" e de "natural". Essa conexão permite-nos reconhecer a complexidade da comunicação atual, cada vez mais permeada por indivíduos e artefatos digitais.

Caracterizada pelo aumento de dispositivos e conexão em rede, a comunicação tem exigido novas formas de apropriação da mídia e da informação. Reconhecendo as múltiplas formas de aprendizagem que envolvem mídia e informação, em 2013, em Abuja, na Nigéria, foi lançada a Aliança Global de Parcerias em Literacias de Mídia e Informação (Gapmil) ${ }^{77}$.

O Gapmil é uma iniciativa conjunta da Unesco e de outras entidades, como a Aliança das Nações Unidas das Civilizações (Unaoc) e o Fundo das Nações Unidas para a Infância (Unicef), que busca promover a cooperação internacional para assegurar que todos os cidadãos tenham acesso às competências de mídia e informação. Concebidas no âmbito das MIL Literacias de Mídia e Informação, tais competências e habilidades reunidas pela Unesco englobam ${ }^{88}$ literacia midiática; literacia informacional; liberdade de expressão e literacia informacional; literacia no uso de bibliotecas; literacia no acesso a notícias; literacia computacional; literacia no uso da Internet; literacia digital, literacia cinematográfica; literacia no uso de jogos; literacia televisiva; literacia publicitária.

Em meio ao fluxo de mídia e informação nos dias de hoje, desponta a percepção do sujeito sob a ótica proposta por Alvin Toffler (1980), que cunhou o termo "prosumer". A partir da junção das palavras em inglês "producer" e "consumer" (em português: prossumidor, resultante da união entre as palavras produtor e consumidor), o termo "prosumer" faz referência à concomitância de produção e consumo de conteúdo. Assim, a comunicação caracteriza-se como potencial duplo fluxo de troca de informação e 
conhecimento, possível graças ao desempenho dos atores em rede como "producers" e, principalmente, fazendo uso das MIL.

O termo "prosumer" e o indivíduo que atua no âmbito da mídia e informação estabelecem uma relação direta, pois tem a ver com produção e consumo, partindo das competências e da apropriação de formatos, linguagens, conteúdos, etc. Como destaca "Autora deste artigo" (2017, p. 303), "o termo, criado em um contexto econômico e adotado em debates acerca da comunicação em rede, possível graças ao advento da Internet, é consoante à visão dialética do indivíduo e sua atuação no âmbito da mídia e informação". Assim, o acesso dos atores em rede à mídia e à informação possibilita o exercício das MIL.

Considerando a emergência das MIL no contexto da "modernidade líquida", do ciberespaço e da cibercultura, marcado pela disseminação dos dispositivos móveis, aumento dos níveis de acesso à Internet e participação da população conectada na produção e consumo de conteúdo, faz se necessário reconhecer o mercado brasileiro de articulação de redes sociais. Diante dessa demanda, o item abaixo se dedica a esse quesito, tanto na perspectiva de identificar as principais necessidades de grandes empresas, como para aferir os principais departamentos responsáveis pelas atividades em rede, além da formação universitária de seus profissionais.

\section{Características do mercado brasileiro de articulação de redes sociais}

A partir do contexto supracitado, desenvolveu-se uma pesquisa quantitativa, desenvolvida por "Autor deste artigo" (2014), e que já teve os procedimentos detalhados no item "Metodologia" do presente artigo, em que foram constatados diversos aspectos da articulação de redes sociais, especialmente com base em 128 questionários respondidos por grandes empresas.

Nesse sentido, em primeiro lugar, diante das respostas obtidas, identificou-se que as empresas que responderam ao questionário têm como objetivo principal, de maneira soberana, o relacionamento com públicos de interesse, com $78,1 \%$. Na sequência, aparece a divulgação de novos serviços e produtos, com 14,8\%. Em seguida, 5,5\% das empresas respondentes assinalaram usar redes sociais para oferecer suporte ao cliente. Por fim, apenas 1,6\% indicaram a busca por informar os stakeholders, como indica o Gráfico 1. 
Gráfico 1: Relacionamento é o principal objetivo de atuação das empresas nas redes sociais.

\section{Relacionamento é o principal objetivo de atuação das empresas nas redes sociais}

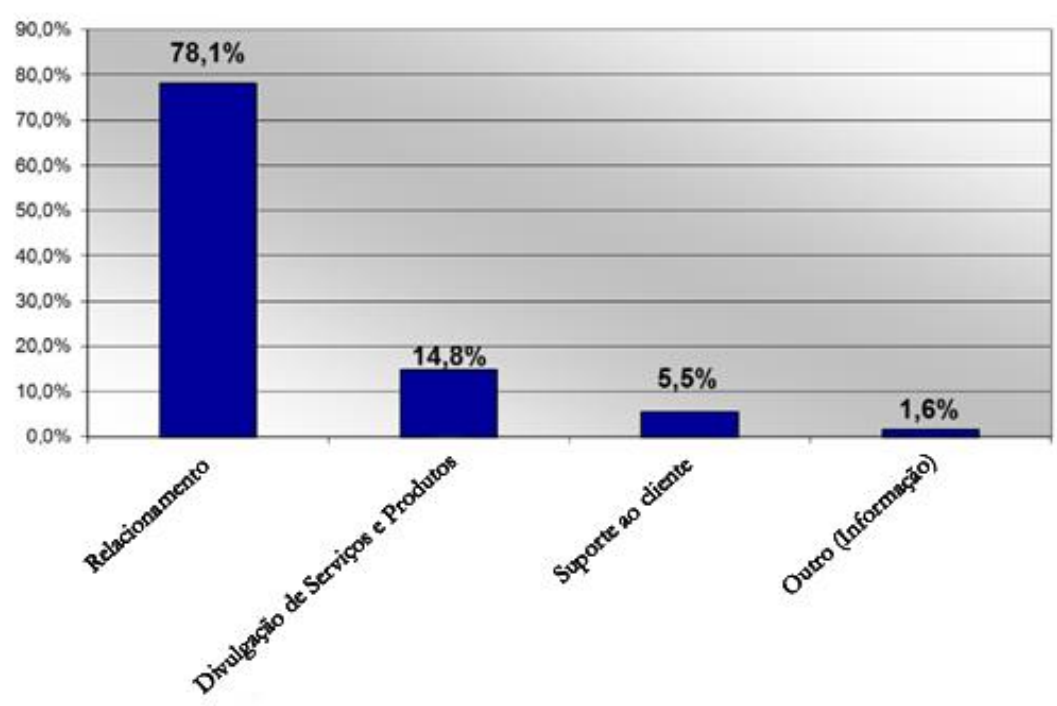

Entende-se que a significativa discrepância entre os objetivos ocorre em decorrência da importância do relacionamento para o fortalecimento da reputação. A simples divulgação de produtos ou o envio de informações, sem o diálogo, não gera tantos benefícios para as empresas, como indica Agatha Camargo Paraventi (2011, p. 212), uma vez que a comunicação "destinada a apenas informar os públicos sobre os assuntos que são de interesse exclusivo da organização, não voltada aos reais interesses dos stakeholders e sem abertura de diálogo, pouco agregará aos objetivos organizacionais”. Ou seja, "configurará apenas a satisfação de ego de uma cúpula diretiva pouco atenta às relações dinâmicas com os públicos que determinam o desenvolvimento das instituições".

Em segundo lugar, entendeu-se ser importante averiguar a maneira como a articulação de redes sociais era realizada. Percebeu-se, então, que, especialmente no Twitter, essa atividade era realizada por colaboradores que já trabalham internamente nas empresas $(50,7 \%)$. No entanto, a diferença para os serviços prestados de maneira terceirizada (49,3\%), geralmente por Agências de Comunicação, é reduzida (ver Gráfico 2). 
Gráfico 2: Colaboradores internos e terceirizados dividem articulação de redes sociais.

\section{Colaboradores internos e terceirizados dividem articulação de redes sociais}

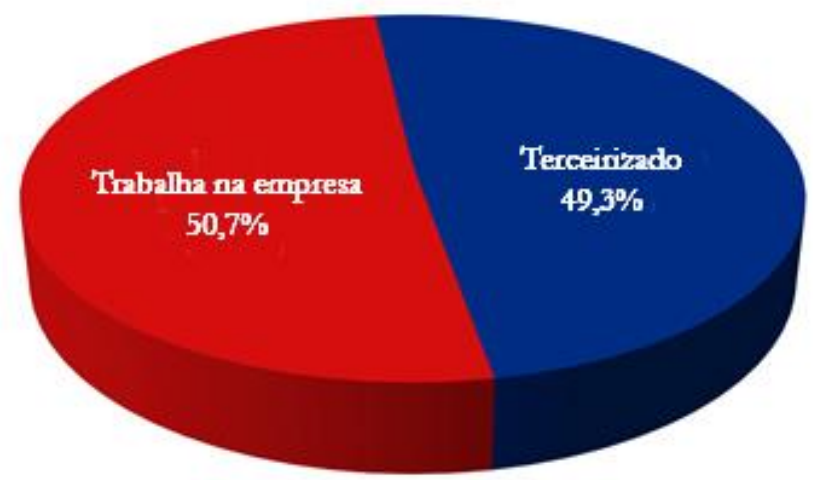

Em terceiro lugar, buscou-se avaliar qual era a principal Área ou Departamento responsável por atividades no ambiente digital e identificou-se que, ao avaliar conjuntamente colaboradores internos e terceirizados, especialmente no que tange à responsabilidade por atividades em redes sociais, a área de Comunicação é predominante, com 42,1\%. Em seguida, também em posição de destaque, aparece a área de Marketing, com 32,5\%. Posteriormente, aparecem os departamentos específicos de redes sociais, com 18,3\%. E, por último, a articulação informal por parte de colaboradores, com 7,1\% (ver Gráfico 3). 
Gráfico 3: Área de comunicação lidera atividades em redes sociais.

\section{Área de Comunicação lidera atividades em redes sociais}

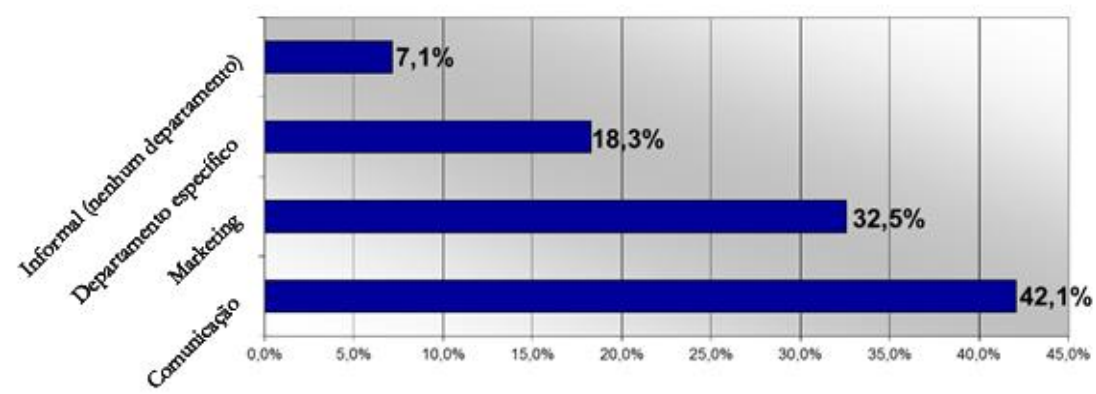

5. Defasagem na formação dos profissionais de Comunicação que articulam redes sociais de grandes empresas

Apesar de dominadas pela Área de Comunicação, as atividades de empresas nas redes sociais ainda possuem algumas falhas decorrentes da defasagem de formação desses profissionais no que tange à tecnologia. É o que indica uma pesquisa qualitativa, realizada por "Autor deste artigo" (2014). Como ressaltam Jean-Pierre Deslauriers e Michèle Kérisit (2008, p. 130), "uma pesquisa qualitativa de natureza exploratória possibilita familiarizar-se com as pessoas e suas preocupações".

Nesse sentido, decidiu-se realizar seis entrevistas em profundidade com representantes de grandes Agências de Comunicação brasileiras responsáveis pela articulação de redes sociais para grandes empresas do Brasil, já mencionadas no item "Metodologia" deste artigo.

De modo geral, é possível dizer que os entrevistados mencionaram que os colaboradores que trabalham com articulação de redes sociais precisam ter uma visão global da empresa a que prestam o serviço.

O entrecruzamento de campos do conhecimento e de formações universitárias diversas também é incentivado, misturando técnicas de Comunicação, Marketing, Recursos Humanos e Tecnologia da Informação (TI), por exemplo. 
Estimular-se-ia a capacitação de um profissional, que poderia ser, por exemplo, de Comunicação, mas que dominasse outras áreas do conhecimento, para aplicar tanto a parte de humanas, focada no conteúdo, como a de ciências ditas duras, com o uso de determinadas linguagens de programação que facilitem o desenvolvimento de aplicativos e gadgets que otimizem o relacionamento entre empresas e públicos de interesse. Ou seja, um profissional capaz de exercer o papel de intermediário no diálogo com outras áreas, promovendo fortalecimento conjunto da empresa, a cooperação mútua e, por consequência, soluções de relacionamento que facilitem o fortalecimento da reputação corporativa.

É preciso ressaltar, no entanto, que o profissional ideal, acima mencionado, na visão dos coordenadores e diretores entrevistados, ainda estava, no período, distante de ser encontrado. Eduardo Gomes Vasques (2014), o Coordenador de Mídias Sociais do Grupo TV1, por exemplo, ressalta que: "O problema que existe hoje, para contratar profissionais nessa área digital, é que ou a pessoa entende muito de mídias sociais e pouco de comunicação ou entende muito de comunicação e pouco de mídias sociais. É muito difícil achar alguém que consiga unir esses dois tipos de conhecimento".

$\mathrm{Na}$ mesma linha de raciocínio, André Giuliese (2014), Diretor Geral da CDN, que indica que o profissional de Comunicação precisa entender minimamente "a lógica de programação para saber como as plataformas de redes sociais funcionam e ser capaz de sugerir novas soluções, com uma visão de comunicação que o programador geralmente não possui”.

Diante dessa possível defasagem de formação dos estudantes de Comunicação, que entraram no mercado recentemente, especialmente no que tange à tecnologia, decidiu-se realizar uma pesquisa qualitativa, com base em entrevistas em profundidade com coordenadores de curso de Comunicação, e uma pesquisa documental, baseada na análise de matrizes curriculares desses cursos. Ambas serão apresentadas no próximo item do artigo. 


\section{Análise de Instituições de Ensino Superior que oferecem o curso de Graduação em Comunicação (Relações Públicas): pesquisa qualitativa e pesquisa documental}

Diante da impossibilidade de se analisar todos os cursos que envolvem a área de Comunicação, utilizou-se um recorte voltado para os cursos de Graduação em Relações Públicas, uma vez que, de acordo com Luiz Alberto de Farias (2009, p. 145),

[...] as relações públicas apresentam, assim, uma função dialógica, por meio da qual criam campo de pensamento que permite o equilíbrio entre interesses por meio de interpretação de significados e da ação pontual ou permanente de integração entre acontecimentos e as suas teias de representações nos espaços simbólicos de disputa e de conflitos e, possivelmente, de encontro e diálogo.

No mesmo sentido, segundo Maria Aparecida Ferrari (2006, p. 87), uma das funções básicas da atividade de relações públicas é a função comunicacional, o que geraria o processo de relacionamento da organização com os stakeholders, possibilitando criar um conceito positivo e duradouro na opinião e no comportamento das pessoas. Nesse sentido, o resultado dessa relação agregaria valores tanto para públicos como para a organização envolvida.

Ou seja, a base das atividades de RP, o relacionamento, é um importante componente para o fortalecimento da reputação corporativa, utilizando-se essa afinidade para o recorte realizado na pesquisa apresentada a seguir.

É nesse contexto que na Tese de Doutorado de "Autor deste artigo" (2017), base para os resultados apresentados neste texto, foram desenvolvidas duas pesquisas, sendo uma qualitativa e uma documental.

$\mathrm{Na}$ pesquisa qualitativa, para analisar as 10 entrevistas em profundidade, com representantes de universidades já mencionados no item "Metodologia" deste artigo, seguiu-se a proposta de Laurence Bardin (2016), em que foram definidas as seguintes categorias temáticas para a Análise de Conteúdo: "Perfil dos coordenadores e suas principais atividades"; "Estrutura Organizacional: Coordenação dos cursos de RP”; "Presença de disciplinas de tecnologia na matriz curricular"; "Influência das Diretrizes Curriculares Nacionais (DCNs)"; "Infraestrutura de tecnologia disponível nos cursos de RP"; e "Relação entre universidades e egressos". 
Para atingir o objetivo do presente artigo, ressaltam-se principalmente os aspectos ligados à "Presença de disciplinas de tecnologia na matriz curricular". Nesse sentido, identifica-se, pelas entrevistas concedidas por coordenadores de curso, que a maioria absoluta indica aumento no número de disciplinas de tecnologia e ampliação na carga horária referente a essa temática, como afirma Ana Luisa Baseggio (2017), coordenadora da PUCRS: "Na realidade, nós buscamos [...] preparar mais adequadamente esse profissional para atuar no mercado [...] Então, nós procuramos sempre entender e atender ao que o mercado da Comunicação está exigindo, tentando trazer atualizações para cá, sempre ressaltando que produção de conteúdo é uma coisa e o uso de tecnologia é outra”.

Ainda nessa temática, existem cursos de Graduação em RP que discutem questões ligadas à tecnologia apenas em disciplinas específicas. Todavia, o mais usual é que essa discussão, atualmente, além de ocorrer desse modo, também perpasse outras disciplinas e atividades complementares.

Também é ressaltada a presença gradativa e ampliada de discussões sobre tecnologia nos cursos de Relações Públicas nos cursos universitários de Comunicação, especialmente na busca por uma aproximação com o mercado de trabalho, que tem investido cada vez mais nesse segmento, como afirma Helenice Carvalho (2017), coordenadora da UFRGS “O que nós começamos a perceber aqui na região, é que a empregabilidade na área de Relações Públicas tem sido cada vez maior na área de Web, gestão de sites, gestão de redes sociais. [...] A empregabilidade em Relações Públicas migrou desse foco tão grande em Comunicação Interna e Comunicação Organizacional para a gestão da imagem e reputação na Web”.

No que diz respeito às disciplinas de tecnologia, as IES possuem, em geral, no mínimo uma disciplina teórica e uma prática. Todavia, a predominância é por disciplinas que consigam mesclar as duas características.

Diante dessas constatações apresentadas, abordar-se-á, a partir de agora, uma pesquisa documental, em que foi realizada a análise das matrizes curriculares das mesmas 10 universidades brasileiras, já mencionadas no item "Metodologia" deste artigo.

Primeiro foi feita uma análise individual da matriz curricular de cada umas das IES dos anos de 2013 e 2016, avaliando-se o aumento - ou não - do número de disciplinas de tecnologia e carga horária relativa ao tema informados pelos 
coordenadores de curso. Em seguida, realizou-se uma análise conjunta das IES brasileiras selecionadas.

Nesse sentido, dentre as IES analisadas, somando-se disciplinas obrigatórias e disciplinas optativas/eletivas, de maneira geral, é possível afirmar que, no Brasil, as universidades costumam ter, cada vez mais, considerável atenção às informações estruturadas transmitidas aos alunos sobre tecnologia, uma vez que a média da somatória de 2013 era de 4 disciplinas oferecidas e passou para 6 disciplinas, em 2016, um aumento de 50\%.

Realizando-se uma análise mais completa, não apenas calcada no número de disciplinas, como, também, na Carga Horária $(\mathrm{CH})$, nota-se que das 10 matrizes curriculares analisadas, 7 tiveram aumento significativo, no número de disciplinas de tecnologia, entre 2013 e 2016.

Além disso, percebe-se que, em 2013, a maioria dos cursos costumava oferecer disciplinas de tecnologia da metade para o final do curso e, em 2016, com o aumento da $\mathrm{CH}$ dedicada a essa temática, a distribuição pela matriz curricular passou a ocorrer desde o início do curso.

O que se percebe, após a pesquisa qualitativa e a pesquisa documental, é que as disciplinas específicas de tecnologia tratam de temas como: regulamentação do uso da tecnologia; Comunicação Digital nas organizações; modelos de negócios em Comunicação Digital; produção de conteúdo para mídias sociais; gestão de relacionamento por meio de mídias sociais; e processos colaborativos em rede. Além disso, também é contemplada outra parte mais técnica, com a articulação de redes sociais, como Facebook, Twitter, Instagram, Snapchat e YouTube, e até o desenvolvimento de portais de Internet, como parte integrada de um planejamento estratégico, envolvendo: computação gráfica; design de interface; arquitetura da Informação; e programação para Internet.

Erica Hiwatashi (2017), coordenadora da Unisinos, uma das entrevistadas na pesquisa qualitativa resume alguns desses aspectos ao relatar que a nova matriz curricular do curso de Graduação de sua universidade busca habilitar o estudante a lidar mais adequadamente com a Comunicação Digital: "A ideia foi organizar o pensamento e habilitar minimamente o aluno a produzir, de forma autônoma, um trabalho de Comunicação Digital em uma empresa”.

Pode-se dizer que, no Brasil, ao longo dos últimos quatro anos, as universidades demonstram ter aumentado a sua preocupação com o tema "tecnologia", buscando, por meio de disciplinas específicas, desenvolver 
habilidades e competências para propiciar ao futuro profissional lidar mais adequadamente com plataformas digitais, o que podem facilitar $\mathrm{o}$ relacionamento por meio da Web e, por consequência, fortalecer a reputação corporativa, como pode ser observado no próximo item do artigo.

\section{Identidade, imagem e reputação: relacionamento entre empresas e stakeholders com o intuito de fortalecimento da reputação corporativa na rede}

É diante desse aumento no número de disciplinas de tecnologia nas matrizes curriculares nos cursos de Comunicação e, em especial, nos de Relações Públicas, que amplia-se a possibilidade de uma atuação mais efetiva da articulação de redes sociais, por parte dos profissionais de Comunicação, para fortalecer a reputação corporativa.

Porém, para atribuir as mudanças provocadas pela rede nesse processo, é preciso, preliminarmente, apresentar a definição e diferença entre identidade, imagem e reputação no contexto organizacional, que, apesar de associados, possuem diferenças conceituais.

A identidade possui relação direta com um conjunto de crenças, valores e princípios internos de uma organização. Está vinculada ao modo como a instituição gostaria de ser percebida, contribuindo para formar a imagem institucional e a reputação corporativa para diferenciar-se de eventuais concorrentes (Capriotti, 2005; Terra, 2011).

Diferentemente do que a empresa deseja projetar, a imagem institucional é vinculada à percepção ou assimilação de determinada pessoa sobre a organização, em virtude de alguma atitude da empresa, muitas vezes de modo momentâneo (Vaz, 1995; França, 2010).

A reputação corporativa, por sua vez, diferencia-se da definição de imagem supracitada, principalmente em decorrência de não ser constituída em um período específico, mas em um processo constante e duradouro, ou seja, ao longo do tempo. Trata-se de uma percepção construída sobre uma organização por parte dos demais atores envolvidos em um processo que envolve três elementos: quem é avaliado, quem analisa e a relação entre ambos. Justamente por não ser formada por fatos pontuais, por não poder ser "copiada", propicia vantagem competitiva à empresa detentora de uma reputação positiva e fortalecida (Argenti, 2006; Recuero, 2008). 
Nesse sentido, é possível que uma empresa possua, em decorrência de experiências vivenciadas em cada segmento da sociedade, mais de uma imagem. Já a reputação costuma ser mais sólida e unificada para a maioria da população e, justamente por essa razão, depende mais fortemente de um relacionamento contínuo, base para os profissionais de Comunicação e foco deste artigo.

A partir desse cenário, é possível vislumbrar diversas oportunidades decorrentes do contexto tecnológico atual. Em contrapartida, o aumento de velocidade na troca de informações e a ampliação do uso de redes sociais têm capacidade de potencializar crítica, injúrias e difamações às empresas (Iasbeck, 1997; Terra, 2008). Isso porque, se presencialmente já existe dificuldade para gerenciar o relacionamento entre empresas e stakeholders, na Web, os empecilhos podem ser ampliados substancialmente, uma vez que o próprio ambiente digital possibilita respostas de maneira praticamente simultânea (Terra, 2008).

É importante ressaltar, nesse sentido, a importância dos públicos para a sobrevivência das empresas. $O$ inverso não se aplica: públicos continuam existindo, independentemente da vontade da organização (Barcellos, 1984; França, 2008). Nesse sentido, de acordo com Fábio França (2008, p. 59), é evidente que "a relação com os públicos é considerada da maior importância: são eles que constroem a imagem da empresa e de sua marca e a empresa depende deles para sobreviver. São essenciais no desenvolvimento de toda a estratégia operacional da empresa”.

Fica perceptível, portanto, a necessidade da prática da comunicação dialógica, uma vez que empresas que demonstração preocupação em relacionar-se com seus stakeholders tendem a recebem apoio da sociedade, valorizando-se e, por conseguinte, aumentando sua chance de fortalecer a reputação corporativa. Para isso, todavia, precisa-se articular as redes sociais com equilíbrio de interesses entre partes envolvidas, mediando conflitos, de modo dinâmico e proativo, gerando compreensão mútua e possivelmente beneficiando ambas as partes.

Ou seja, partindo-se dessa premissa, constituir-se-iam mensagens unificadas (unicidade da mensagem) - disseminadas de modo assertivo e coeso, interna e externamente, para públicos de interesse previamente identificados - para possibilitar relacionamentos planejados, consistentes e contínuos, em um ambiente que propicia a liberdade de expressão, como a Internet, gerando possível retorno de reputação e, consequentemente, financeiro (França, 2008; Farias, 2009; Kunsch, 2003; Macnamara, 2010). Nesse contexto, as MIL 
tornam-se fundamentais para a promoção da comunicação dialógica e favorecimento da liberdade de expressão.

Há, em contrapartida, o lado negativo decorrente da possibilidade de inserção de qualquer conteúdo, em qualquer momento, nas redes sociais. Gera-se, nesse sentido, em muitas empresas, insegurança para investir no ambiente Web, que, em muitos momentos, tem debates baseados em informações sem credibilidade, muitas vezes inverídicas, que podem prejudicar a empresa (Jenkins, 2009; Savigny, 2002).

É diante dessa perspectiva que aparecem, cada vez mais frequentemente, maneiras de se monitorar o ambiente Web e aferir a reputação de uma empresa. Se antes, sem a Internet, a avaliação era feita por meio de pesquisas presenciais, que demandavam muito tempo para a divulgação de resultados e, em geral, mensuravam apenas acontecimentos pontuais, refletindo mais em um resultado sobre a imagem institucional e não todo o processo de construção da reputação (Iasbeck, 2007; Lerner, 2006). Agora, em virtude de um novo contexto tecnológico, consegue-se avaliar as opiniões dos stakeholders praticamente em tempo real, com registro de todas as interações do usuário com a empresa ao longo do tempo, o que possibilita analisar as ações que obtiveram resultados piores ou melhores em determinado período (Nielsen, 1999; Macnamara, 2010).

Esse monitoramento constante da forma como a empresa é vista por seus públicos de interesse é imprescindível para adaptar o modo como o relacionamento é realizado, influenciando diretamente na maneira como formadores de opinião "irão emitir e influir positiva ou negativamente" no que a sociedade pensará sobre a empresa (Ferrari, 2010, p. 894).

É com essa gestão, que auxilia empresas a se posicionarem perante stakeholders, "demonstrando qual é a razão de ser do empreendimento, isto é, sua missão, quais são os seus valores, no que acreditam e o que cultivam, bem como a definirem uma identidade própria e como querem ser vistas no futuro" (Kusnch, 2006, p. 34), que será possível diminuir as chances de que a sociedade posição contrária à organização e, consequentemente, a empresa permaneça com uma reputação sólida ou, até se fortaleça. 


\section{Considerações Finais}

O presente artigo trata da reputação corporativa na Web, considerando dois eixos principais: o mercado brasileiro de articulação de redes sociais e a formação dos profissionais de Comunicação.

De modo geral, este artigo suscita o debate acerca da reputação das organizações em meio às transformações cada vez mais rápidas e transitórias da "modernidade líquida" (Bauman, 2001). Tais ações acompanham os avanços das tecnologias digitais e, por consequência, concentram-se cada vez mais em estratégias de relacionamento na Web.

Embora muitas organizações já desenvolvam atividades pautadas na articulação das redes sociais, ainda observa-se uma defasagem em relação à formação dos profissionais que atuam no âmbito da comunicação organizacional, principalmente no que diz respeito ao desenvolvimento de soluções de tecnologia focadas no fortalecimento da reputação. Para compreender essa defasagem, foram analisadas algumas das mais importantes IES brasileiras. O resultado aponta aumento significativo no número de disciplinas de tecnologia e na carga horária relativa ao tema entre 2013 e 2016.

Desse modo, é possível vislumbrar que os profissionais de Comunicação podem chegar mais preparados para atuar no ambiente online, marcado pelo intenso fluxo de trocas informações e consumo/produção de conteúdo pelos "prosumers".

Sob essa perspectiva, reconhece-se a importância das MIL - Literacias de Mídia e Informação para capacitar os indivíduos no uso da mídia e informação. Embora as MIL, sobretudo as literacias digitais, ampliem as habilidades da população cada vez mais conectada, não se pode desconsiderar uma possível desilusão das organizações que investem no relacionamento com seus stakeholders e buscam resultados imediatos que fortaleçam a reputação corporativa na rede. Isso porque o investimento em estratégias voltadas ao fortalecimento da reputação não corresponde ao caráter emergencial que permeia os fluxos comunicacionais na rede.

Mais do que uma ação imediata que possa alavancar a imagem da marca, acredita-se que o RP e os demais profissionais de Comunicação devam investir em relacionamento, de modo a construir uma relação a longo prazo com os stakeholders e que possam, efetivamente, colaborar com a construção da reputação corporativa na Web. 
Assim sendo, além dos conhecimentos sobre tecnologia, redes sociais e literacias digitais, é necessário pensamento crítico para identificar ameaças e oportunidades que se desenham no mercado e impactam diretamente as organizações inseridas no contexto da sociedade contemporânea hiperconectada.

\section{Referências}

Anuário Brasileiro da Comunicação Corporativa 2012. (2012). São Paulo: MegaBrasil.

Argenti, P. A. (2006). Comunicação empresarial: a construção da identidade, imagem e reputação. Rio de Janeiro: Elsevier, 79-108.

Barcellos, F. (1984). Curso Básico de Relações Públicas. São Paulo: Ediouro.

Bardin, L. (2016). Análise de Conteúdo (Trads. Luís Antero Reto e Augusto Pinheiro). $3^{a}$ reimp. da $1^{a}$ ed. de 2016. Lisboa: Edições 70 (Obra original publicada em 1977).

Baseggio, A. L. (2017). Entrevista concedida a "Autor deste artigo" em 08 de set. 2016.

Bauman, Z. (2001). Modernidade líquida. Rio de Janeiro: Zahar.

Bauman, Z. (2013). Sobre educaşão e juventude: conversas com Riccardo Mazzeo. Rio de Janeiro: Zahar.

Bittencourt, H. R., Casartelli, A. O., Rodrigues, A. C. M. (2009). Sobre o Índice Geral de Cursos (IGC). In: Avaliação, Campinas; Sorocaba, SP, v. 14, n. 3, 667-682. Disponível em: http://www.scielo.br/pdf/aval/v14n3/a08v14n3.pdf. Acesso em: 20 fev. 2017.

Capriotti, P. (2005). Planificación estratégica de la imagen corporativa. 2. ed. Barcelona: Editora Ariel, 69-92.

Carvalho, H. (2017). Entrevista concedida a "Autor deste artigo" em 01 de set. 2016. 
Castells, M. (2003). A galáxia da internet: reflexões sobre a internet, os negócios e a sociedade. Rio de Janeiro: Zahar.

Deslauriers, J. P., Kérisit, M. (2008). O delineamento de pesquisa qualitativa. In: POUPAR, Jean et al. A Pesquisa Qualitativa: Enfoques epistemológicos e metodológicos. Petrópolis, RJ: Vozes, 127-153.

Exame. (2013). Melhores \& maiores: as 1000 maiores empresas do Brasil. Revista Exame, edição especial dos 40 anos. São Paulo, Editora Abril.

Farias, L. A. (2009). Relações públicas e sua função dialógica. Organicom Revista Brasileira de Comunicação Organizacional e relações Públicas, a. 6, n. 10/11, 142-147.

Ferrari, M. A. (2006). As dimensões locais das relações públicas internacionais: teorias e paradigmas. Organicom - Revista Brasileira de Comunicaşão Organizacional e relações Públicas, a. 3, n. 5, 83-85.

Ferrari, M. A. (2010). Opinião Pública e RP. In: MELO, José Marques de (Org.). Enciclopédia INTERCOM de Comunicação. São Paulo: Sociedade Brasileira de Estudos Interdisciplinares da Comunicação, 893-894.

Fortes, W. G. (2003). Relações Públicas: Processo, Funções, Tecnologia e Estratégias. 3. ed. São Paulo: Summus.

França, F. (2010). Imagem corporativa. In: MELO, José Marques de (Org.). Enciclopédia INTERCOM de comunicação. São Paulo: Sociedade Brasileira de Estudos Interdisciplinares da Comunicação, 654-655.

França, F. (2008). Públicos: como identificá-los em uma nova visão estratégica. 2. ed. São Caetano do Sul, SP: Yendis Editora.

Freeman, R. E., Reed, D. L. (1983). Stockholders and Stakeholders: A New Perspective on Corporate Governance. California Management Review, Vol. XXV, n. 3, 88-106. Disponível em: <http://trebucq.ubordeaux4.fr/Stock\&stakeholders.pdf>. Acesso em: 16 jul. 2016.

Giuliese, A. (2014). Entrevista concedida a "Autor deste artigo" em 09 mai. 2012.

Hiwatashi, E. (2017). Entrevista concedida a "Autor deste artigo" em 23 de ago. 2016. 
Iasbeck, L. C. A. (1997). A administração da identidade: um estudo semiótico da comunicação e da cultura nas organizações. Tese (Doutorado) - Programa de Pós-Graduação em Comunicação e Semiótica. São Paulo: PUC-SP.

Iasbeck, L. C. A. (2007). Imagem e reputação na gestão da identidade organizacional. Revista Organicom, São Paulo, ano 4, n. 7, 84-97.

Jenkins, H. (2009). Cultura da Convergência. São Paulo: Aleph.

Kunsch, M. M. K. (2006). Gestão das Relações Públicas na

Contemporaneidade e a sua institucionalização profissional e acadêmica no Brasil. Revista Organicom, São Paulo, ano 3, n.5, 30-61.

Kunsch, M. M. K. (2003). Planejamento de Relações Públicas na Comunicação Integrada. São Paulo, Summus.

Kunsch, M. M. K. (2007). Comunicação organizacional na era digital: contextos, percursos e possibilidades. Signo y Pensamiento 51. Volume XXVI. Colombia, Universidad Javeriana: Facultad de Comunicación y Lenguage.

Latour, B. (2012). Reagregando o social. Salvador: Edufba.

Lerner, E. B. (2006). A Relação entre Responsabilidade Social Corporativa e Reputação Corporativa. Disponível em:

<http://tede.mackenzie.br/jspui/handle/tede/698>. Acesso em: 22 jul. 2016.

Lévy, P. (1999). Cibercultura. São Paulo: Ed. 34.

Macnamara, J. (2010). The 21st Century Media (R)evolution: Emergent Communication Practices. New York: Peter Lang.

Nielsen, J. (1999). Reputation Managers are Happening. Disponível em: <http://www.useit.com/alertbox/990905.html>. Acesso em: 14 jul. 2016.

Otoni, A.C. (2015). Brasileiros gastam 650 horas por mês em redes sociais. $O$ Globo. Disponível em: <http://blogs.oglobo.globo.com/nasredes/post/brasileiros-gastam-650-horas-por-mes-em-redes-sociais567026.html>. Acesso em Acesso em 20 de abril de 2017.

Paraventi, A. C. (2011). Uso estratégico das publicações na gestão dos relacionamentos organizacionais. In: FARIAS, Luiz Alberto de (Org). Relações 
públicas estratégicas: técnicas, conceitos e instrumentos. São Paulo: Summus, 195-234.

Recuero, R. (2008). O que é Mídia Social?. Disponível em $<$ http://pontomidia.com.br/raquel/arquivos/o_que_e_midia_social.html>. Acesso em: 28 fev. 2017.

Saad, B. (2012). Estratégias 2.0 para a mídia digital: internet, informação e comunicação. $3^{a}$ ed. São Paulo, Editora Senac São Paulo.

Savigny, H. (2002). Public Opinion, Political Communication and the Internet. Politics, v. 22, n. 1, 1-8.

Severino, J. A. (2016). Metodologia do Trabalho Cientifico. 24. ed. rev. e atual. São Paulo: Cortez.

Terra, C. F. (2008). Blogs corporativos: modismo ou tendência?. São Caetano do Sul, SP: Difusão.

Terra, C. F. (2011). Mídias sociais... e agora? - O que você precisa saber para implementar um projeto de mídias sociais. São Caetano do Sul, SP: Difusão.

Toffler, A. (1980). A terceira onda. 8a . ed. Rio de Janeiro: Record.

Vasques, E. G. (2014). Entrevista concedida a "Autor deste artigo" em 11 mai. 2012.

Vaz, G. N. (1995). O Mercado de Idéias e Imagens. In: Marketing institucional: o mercado de idéias e imagens. São Paulo: Pioneira, 34-57.

“Autor deste artigo”. (2017). Literacias digitais nos cursos de Graduação em Relações Públicas: disciplinas de tecnologia nas matrizes curriculares de universidades brasileiras. Tese (Doutorado) - Escola de Comunicações e Artes, Programa de PósGraduação em Ciências da Comunicação, Universidade de São Paulo, São Paulo. Disponível em: <http://www.teses.usp.br/teses/disponiveis/27/27154/tde-31052017115431/pt-br.php>. Acesso em: 2 jun. 2017.

"Autor deste artigo". (2014). Relações públicas, mercado e redes sociais. São Paulo: Summus Editorial. 
“Autora deste artigo" (2017). A ressignificação da pesquisa-ação do NACE Escola do Futuro - USP: análise dos principais projetos sob a ótica das Literacias de Mídia e Informação (MIL). Tese (Doutorado) - Escola de Comunicações e Artes, Programa de Pós-Grad*uação em Ciências da Comunicação, Universidade de São Paulo, São Paulo. Disponível em:

<http://www.teses.usp.br/teses/disponiveis/27/27154/tde-30052017155706/>. Acesso em: 2 jun. 2017.

Wilson, C., Grizzle, A., Tuazon, R., Akyempong, K., Cheung, C. K. (2013). Alfabetização midiática e informacional: currículo para a formação de professores. Brasília: Unesco, UFTM.

\section{Notas}

${ }^{1}$ Disponível em: <http://cetic.br/pesquisa/domicilios/>. Acesso em 19 de abril de 2017.

2 As seis Agências de Comunicação brasileiras selecionadas foram: CDN Comunicação Corporativa; Edelman Significa; FSB Comunicações; Grupo Máquina Public Relations; Grupo TV1 Comunicação e Marketing; e In Press Porter Novelli)

3 Disponível em: <http://emec.mec.gov.br/>. Acesso em 06 de novembro de 2016.

4 O IGC (Índice Geral de Cursos) refere-se a uma avaliação ampla e completa de todos os cursos da Instituição de Ensino Superior. Para atribuir uma nota, que varia entre 1 e 5, são computados, por exemplo, a infraestrutura, o Corpo Docente, a nota do ENADE, a Pós-Graduação, entre outros critérios, não só especificamente de um curso (no caso, Relações Públicas), como de todos da IES (Bittencourt, Casartelli, \& Rodrigues, 2009).

5 O IGC Contínuo é uma média ponderada das notas de todos os cursos de uma IES ao longo dos anos, relacionando-se diretamente com o Índice Geral de Cursos (Bittencourt, Casartelli, \& Rodrigues, 2009).

${ }^{6}$ Stakeholders, também conhecidos como "públicos de interesse" ou "partes interessadas", são indivíduos ou grupos que influenciam e são afetados pelas atividades de uma organização. Em geral, se constituem por clientes, 
colaboradores, fornecedores, e parceiros (Fortes, 2003; Freeman \& Reed, 1983).

${ }^{7}$ Informações em: <http://www.unesco.org/new/en/communication-andinformation/media-development/media-literacy/global-alliance-forpartnerships-on-media-and-information-literacy/about-gapmil/>. Acesso em: 30 de outubro de 2016.

8 A versão em português do documento "Currículo para Formação de Professores" (Wilson, Grizzle, Tuazon, Akyempong, \& Cheung, 2013) substitui o termo literacia por alfabetização. 


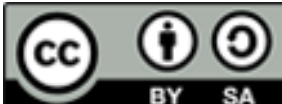

Licencia Creative Commons

Miguel Hernández Communication Journal

mhjournal.org

\section{Cómo citar este texto:}

Fabiana Grieco Cabral de Mello Vetritti y Rafael Vergili (2017): "Reputação corporativa na Web: reflexões acerca da formação em Comunicação e da articulação de redes sociais no Brasil", en Miguel Hernández Communication Journal, nº, pp. 435 a 464. Universidad Miguel Hernández, UMH (Elche-Alicante). Recuperado el _ de de 20 de: [link del artículo en mhjournal.org] 